University of Wollongong

Research Online

Australian Institute for Innovative Materials -

Papers

Australian Institute for Innovative Materials

$1-1-2019$

Facile development of a fiber-based electrode for highly selective and sensitive detection of dopamine

Syamak Farajikhah

University of Sydney, sf998@uowmail.edu.au

Peter C. Innis

University of Wollongong, innis@uow.edu.au

Brett Paull

University of Tasmania

Gordon G. Wallace

University of Wollongong, gwallace@uow.edu.au

Alexander R. Harris

University of Wollongong, alexh@uow.edu.au

Follow this and additional works at: https://ro.uow.edu.au/aiimpapers

Part of the Engineering Commons, and the Physical Sciences and Mathematics Commons

Research Online is the open access institutional repository for the University of Wollongong. For further information contact the UOW Library: research-pubs@uow.edu.au 


\title{
Facile development of a fiber-based electrode for highly selective and sensitive detection of dopamine
}

\author{
Abstract \\ A facile one-step method was used to create a selective and sensitive electrode for dopamine (DA) \\ detection based upon a stainless steel (SS) filament substrate and reduced graphene oxide (rGO). The \\ electrode successfully and selectively detects DA in the presence of uric acid and ascorbic acid without \\ the need of a Nafion coating. The proposed electrode is easy to fabricate, low-cost, flexible and strong. \\ The rGO-SS electrode could also be incorporated into a 3-dimensional braided structure enabling DA \\ detection in a two-electrode fibre system. The sensor is an excellent candidate for production of \\ affordable, robust and flexible wearable and portable sensor and expands the application of textiles in \\ point of care diagnostic devices. \\ Disciplines \\ Engineering | Physical Sciences and Mathematics

\section{Publication Details} \\ Farajikhah, S., Innis, P. C., Paull, B., Wallace, G. G. \& Harris, A. R. (2019). Facile development of a fiber- \\ based electrode for highly selective and sensitive detection of dopamine. ACS Sensors, 4 (10), \\ 2599-2604.
}




\title{
Facile development of a fiber-based electrode for highly selective and sensitive detection of dopamine
}

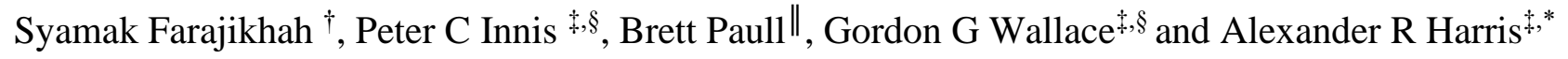 \\ † Institute of Photonics and Optical Sciences (IPOS), School of Physics, The University of Sydney, NSW, 2006, Australia \\ $\$$ ARC Centre of Excellence for Electromaterials Science, Intelligent Polymer Research Institute, University of Wollongong, \\ Wollongong, NSW 2522, Australia \\ ${ }^{\S}$ Australian National Fabrication Facility - Materials Node, Innovation campus, University of Wollongong NSW 2522, Aus- \\ tralia \\ \| Australian Centre for Research on Separation Science (ACROSS) and ARC Centre of Excellence for Electromaterials Sci- \\ ence (ACES), School of Natural Sciences, University of Tasmania, TAS 7005, Australia
}

Supporting Information Placeholder

\begin{abstract}
A facile one-step method was used to create a selective and sensitive electrode for dopamine (DA) detection based upon a stainless steel (SS) filament substrate and reduced graphene oxide (rGO). The electrode successfully and selectively detects DA in the presence of uric acid and ascorbic acid without the need of a Nafion coating. The proposed electrode is easy to fabricate, lowcost, flexible and strong. The rGO-SS electrode could also be incorporated into a 3-dimensional braided structure enabling DA detection in a two-electrode fibre system. The sensor is an excellent candidate for production of affordable, robust and flexible wearable and portable sensor and expands the application of textiles in point of care diagnostic devices.
\end{abstract}

Dopamine (DA) is an important neurotransmitter in the mammalian brain associated with the motivational and movement pathways $^{1,2}$. Abnormal DA levels in the human body are associated with several neurological diseases such as Alzheimer's, and Parkinson's diseases ${ }^{3,4}$. In Parkinson's disease, there is a loss of dopaminergic cells, resulting in rigidity and tremor. The main treatment is levodopamine, which is metabolized in the brain to DA. A simple and accurate method for monitoring DA level is required to manage disease progression and treatment. In recent decades, different DA detection methods such as electrochemical analysis ${ }^{5}$, photoelectrochemical $^{6}$, chemiluminescence ${ }^{7}$, and Localized Surface Plasmon Resonance (LSPR) sensors using silver nanoparticles ${ }^{8}$ have been reported. Among these techniques, electrochemical approaches due to their accuracy, cost-effectiveness and simplicity have been widely used to detect $\mathrm{DA}^{2,9,10}$. An electrochemical approach can be used to detect DA in-situ, allowing real-time response to changes in DA concentrations.

Fast-scan cyclic voltammetry (FSCV), and differential pulse voltammetry (DPV) are typically used for electrochemical detection of $\mathrm{DA}^{11-14}$. FSCV offers outstanding temporal resolution, but it suffers from large capacitance, requiring a background subtraction step. This limits the sensitivity and selectivity of this method. On the other hand, DPV provides high sensitivity and selectivity, but with less temporal resolution ${ }^{5}$.
Poor selectivity of DA detection is caused by uric acid (UA) and ascorbic acid (AA) having very similar redox potentials. To improve the selectivity of DA by electrochemical detection, chemical surface modifications using carbon-based materials ${ }^{3,15}$ and nanoparticles ${ }^{16,17}$ have been widely used ${ }^{18}$. Chemical surface modification of electrodes by carbon nanotubes ${ }^{2}$, polypyrrole doped with sulfonated $\beta$-cyclodextrins ${ }^{19}$, poly $(3,4$-ethylenedioxyselenophene) $(\text { PEDOT })^{3}$ and graphene oxide $(\mathrm{GO})^{15}$ have reported to improve selectivity and lowering the detection limit of $\mathrm{DA}^{20,21}$. Nanoparticle-modified electrodes such as $\beta_{\mathrm{MnO}_{2}}{ }^{17}$, gold nanoparticles ${ }^{14}$, and molybdenum oxide ${ }^{16}$ have also displayed very high selectivity towards DA. As a response to the rapid spread of serious illnesses around the globe, World Health Organisation has prioritised “ASSURED”, affordable, sensitive, specific, user-friendly, rapid and robust, equipment free and deliverable to end user, diagnostic devices $^{22}$. After the first introduction of thread-based microfluidics in $2010^{23,24}$, threads and textiles have been widely used as an important platform for the development of cost-effective sensors. Owing to the unique characteristics of textiles such as fluid wicking, cost-effectiveness, flexibility, ease of incorporation into wearable devices and robustness in wet state $e^{9,25,34,35,26-33}$, textiles have been widely used as a substrate for production of a range of flexible and cost effective detection devices to address the targeted "ASSURED" diagnostic devices. Metallic electrodes for electrochemical sensing have been introduced into textile structures using different methods, i.e. pins and threads ${ }^{36}$ and screen printing ${ }^{37,38}$ which are relatively expensive in low-scale production.

High performance graphene and carbon fibre electrodes have been used for the selective and sensitive detection of DA. Gold nanoparticle-decorated carbon fibre microelectrodes ${ }^{14}$ have been reported for highly sensitive and selective amperometric detection of DA release from PC12 cells. Puthongkham et al. have also reported sensitive and selective detection of DA using modified carbon fibre microelectrodes ${ }^{12}$. PEDOT-modified carbon ${ }^{5}$ and graphene ${ }^{3}$ electrodes have also been reported for sensitive and selective electrochemical detection of DA. However, these fibres are inherently fragile, limiting their lifetime and hindering implantation of these fibres into tissue. Stainless steel (SS) filament is more robust compared to carbon and graphene fibres yet very flexible (Figure S1). These characteristics raise the possibility of the SS filaments being more suitable for wearable and implantable sensors. 
In this paper, we demonstrated a facile one-step approach for the development of a robust yet flexible fibre-based electrode with high sensitivity and selectivity towards dopamine eliminating any postprocessing or modifications, such as electrode oxidation or coating with Nafion, normally required for the development of DA sensors. As a proof of processability, the fibre-based electrode was braided into a 3D textile electrochemical cell and used for successful detection of dopamine.

The surface of SS filament working electrodes were modified by simultaneous electrodepositing and reduction of LCGO. SS filaments were washed with EtOH and DI water to clean surface impurities prior to electrodepositions. To produce consistent and reproducible reduced LCGO (rGO)-coated SS filaments, only $5 \mathrm{~mm}$ of SS filaments were exposed for rGO electrodeposition by isolating SS filaments as shown in Figure 1a. Deposition of rGO was optimized to perform at $-1.2 \mathrm{~V}$ for $5 \mathrm{~min}$.

Visible colour change in the electrode from silver to black after electrodeposition (Figure 1b) and SEM images of rGO-coated SS filaments (Figure S2) confirmed the successful reduction and deposition of rGO on the SS filaments. Raman spectra of SS filament, LCGO and rGO-coated SS filament, shown in Figure 1c, further confirm the formation of rGO layer on SS filament. Characteristic $D$ and $G$ peaks of carbonaceous materials were observed at 1347 and $1586 \mathrm{~cm}^{-1}$, respectively, in Raman spectra of LCGO ${ }^{40,41}$ and the rGO-coated SS filament. It is expected that the electrodeposition partially eliminates oxygen containing groups of LCGO and restores the pi-electron structure to some extent ${ }^{42,43}$. The observed Raman spectra of the rGO-coated SS, D and G bands shifted compare to those of LCGO which is an indication for reduction of graphene oxide ${ }^{40}$. Similarly, the ratio of the $\mathrm{D} / \mathrm{G}$ bands $\left(\mathrm{ID}_{\mathrm{D}} / \mathrm{IG}_{\mathrm{G}}\right.$ ) was noted to increase after electrodeposition (it was measured to be 1.21 in LCGO to 1.35 rGO-coated SS), which has also been attributed to formation of new smaller graphitic domains confirming the reduction of $\mathrm{LCGO}^{41,44-46}$.

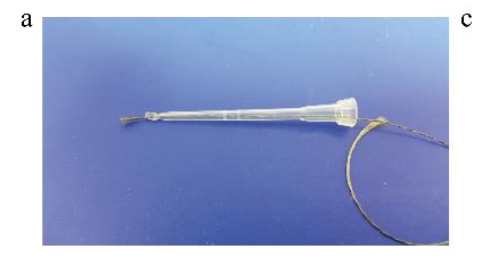

b

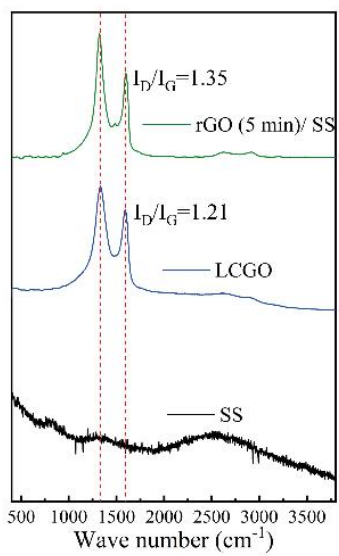

Figure 1- (a) isolated SS filament with $5 \mathrm{~mm}$ exposed, (b) top:rGO-SS and bottom:SS filament and (c) Raman spectra of SS filament, LCGO and rGO-SS filament

The electrochemical response of the rGO-SS and SS filament electrodes in the presence of DA was initially studied by cyclic voltammetry (CV). As shown in Figure 2 a and Figure S3, unmodified SS filament displayed no redox peaks in $200 \mu \mathrm{M}$ DA solution. However, voltammetry of the rGO-SS filament exhibited an anodic peak $\left(E_{\mathrm{pa}}\right)$ and cathodic peak $\left(E_{\mathrm{pc}}\right)$ at about $0.250 \mathrm{~V}$ and $0.100 \mathrm{~V}$, respectively $(\Delta \mathrm{E}=\mathrm{Epc}-\mathrm{Epa} \approx 0.150 \mathrm{~V})$. This indicates that $\mathrm{rGO}$ electrodeposition on SS filament greatly enhanced its electrochemical response to DA. As illustrated in Figure 2b, different concentrations of DA ranging from $1 \mu \mathrm{M}$ to $1 \mathrm{mM}$ in $100 \mathrm{mM}$ PBS were successfully detected using rGO-SS filament electrode. The cathodic peak current increased linearly with DA concentration (Figure $2 \mathrm{c}$ ). The proposed electrode demonstrated broader linear range of detection compared to the previous reported works using carbonbased electrodes or modified electrodes using carbon-based materials ${ }^{5,6,11,18,47,48}$. Table 1 compares the performance this electrode with some other electrodes used to detect DA. Multiple cycle voltammetry showed little change in peak current, indicating the surface modification was stable. To reduce the background capacitance and increase the electrode sensitivity, DPV was also applied. As illustrated in Figure 2d different concentrations of DA in 100 $\mathrm{mM}$ PBS buffer solution ranging from $1 \mu \mathrm{M}$ to $1 \mathrm{mM}$ were successfully detected using rGO-SS filament electrode using the DPV technique. A linear increase in cathodic current with an increase in concentration of DA was observed in low DA concentrations, i.e. up to $5 \mu \mathrm{M}$ DA in $100 \mathrm{mM}$ PBS solution (Figure 2e).
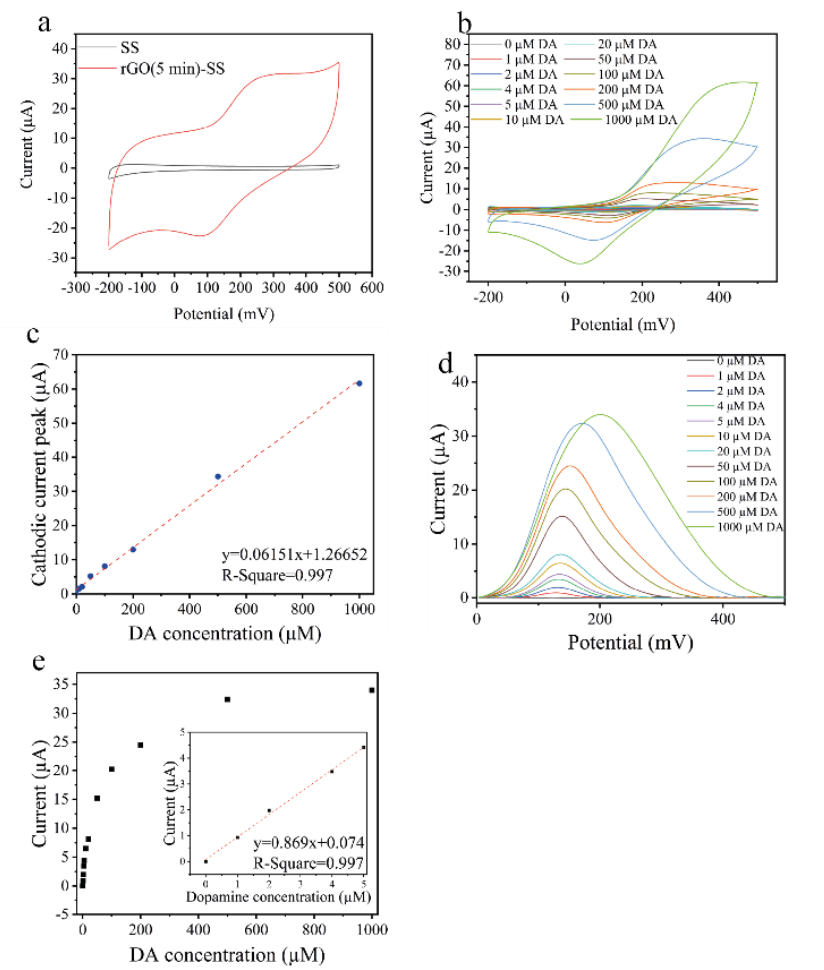

Figure 2- (a) CV curves of $200 \mu \mathrm{M}$ DA in $100 \mathrm{mM}$ PBS at $100 \mathrm{mV}$ $\mathrm{s}^{-1}$ scan rate using SS or rGO-SS working electrodes, (b) CV curves of different concentrations of DA in $100 \mathrm{mM}$ PBS at $100 \mathrm{mV} \mathrm{s}^{-1}$ scan rate, (c) Linear increase in cathodic peak current of $\mathrm{CV}$ curves with increasing DA concentration, (d) DPV curves of different concentrations of DA in $100 \mathrm{mM}$ PBS and (e) Increase in peak cathodic current of DPV curves with increasing DA concentration, inset: linear increase in cathodic current with an increase in concentration of DA up to $5 \mu \mathrm{M}$ 
Table 1. Comparison of linear range and detection limit for electrochemical detection of DA on representative electrode materials

\begin{tabular}{|l|l|l|l|l|}
\hline Electrode & $\begin{array}{l}\text { Linear rage } \\
(\mu \mathrm{M})\end{array}$ & $\mathrm{R}^{2}$ & $\begin{array}{l}\text { LOD } \\
(\mu \mathrm{M})\end{array}$ & Ref. \\
\hline 3D SWNTs-Ppy composite & $5-50$ & 0.998 & 5 & 48 \\
\hline Nafion-coated MWNT & $0.1-5$ & 0.995 & 0.01 & 2 \\
\hline rGO-GCE & $\begin{array}{l}0.1-100 \\
\text { and } \\
100-400\end{array}$ & $\begin{array}{l}0.991 \\
\text { and } \\
0.997\end{array}$ & 0.1 & 15 \\
\hline $\begin{array}{l}\text { molybdenum oxide nanopar- } \\
\text { ticles modified screen printed } \\
\text { carbon paste electrode }\end{array}$ & $0.1-600$ & 0.995 & 0.00 & 16 \\
\hline $\begin{array}{l}\text { PEDOT modified } \\
\text { scribed graphene }\end{array}$ & $1-150$ & 0.995 & 0.33 & 3 \\
\hline $\begin{array}{l}\text { (GQDs- } \\
\text { NHCH2CH2NH)/GCE }\end{array}$ & $1-150$ & 0.996 & 0.11 & 1 \\
\hline Graphene-modified GCE & $4-100$ & 0.988 & 2.64 & 47 \\
\hline rGO-SS & $1-1000$ & 0.997 & $<1$ & $\begin{array}{l}\text { This } \\
\text { work }\end{array}$ \\
\hline
\end{tabular}

Note: SWNTs: single wall carbon nanotubes; Ppy: polypyrrole; GCE: glassy carbon electrode; MWNT: multi wall carbon nanotubes; GQDs: graphene quantum dots

The rGO-SS filament electrode shows excellent selectivity of DA over UA and AA. As shown in Figure 3a and Figure 3b, 25 $\mu \mathrm{M}$ DA in PBS was selectively detected by rGO-SS filament electrode in the presence of UA and AA at ten times higher concentration without any further surface modifications such as Nafion coating. DA is positively charged ${ }^{1}$, while $\mathrm{rGO}$ sheets contain a net negative charge due to the oxygen containing functional groups on the surface $^{5,49}$. Therefore, positively charged amine groups of $\mathrm{DA}(\mathrm{pKa}$ $=8.87$ ) could be attracted to the surface of the rGO-SS filament electrode by electrostatic interaction and $\pi-\pi$ bonding ${ }^{1,18}$. In contrast, $\mathrm{UA}(\mathrm{pKa}=5.75)$ and $\mathrm{AA}(\mathrm{pKa}=4.1)$ are negatively charged, which can result in electrostatic repulsion from the rGO-SS filament electrode ${ }^{1,18,49}$. Reaction mechanism of DA on rGO-SS filament electrode is illustrated schematically in Figure 3c. Although the proposed electrode is highly selective to DA over AA and UA, increasing the rGO electrodeposition time (from 5 to 10 minutes) resulted in an electrode sensitive to DA and UA (Figure S4). This can be attributed to the higher degree of GO reduction, removal of oxygen functionality and consequently more neutral surface charge ${ }^{46}$. This was confirmed by Raman spectra, which exhibited an increase in the intensity ratio of the $D$ and $G$ bands $\left(I_{D} / I_{G}\right)$ for the electrode prepared by 10 minutes electrodeposition compared to that of prepared by five minutes (Figure S4a).
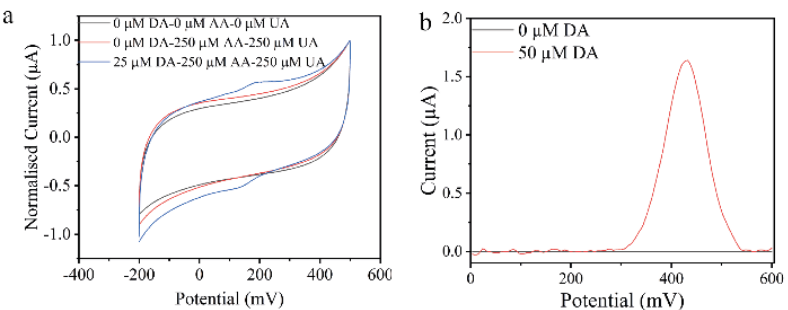

$\mathrm{c}$

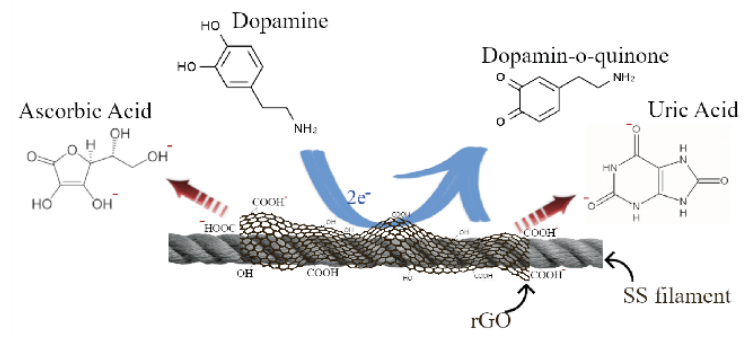

Figure 3- DA selectively being detected in the presence of UA and AA at ten times higher concentration using (a) CV and (b) DPV methods, and (c) schematic of the reaction mechanism of DA on the rGO-SS filament electrode

As a proof of processability of the electrodes, a 3D braided structure comprising two parallel SS electrodes, using the method we have previously shown ${ }^{40}$, was fabricated. Separated electrodes in a braided structure are shown in Figure 4a. The working electrode in the braided structure was modified by electrodeposition of rGO using the method described earlier. Figure $4 \mathrm{~b}$ shows the structure with modified working electrode. As a proof of concept, a 3D braided structure with modified working electrode was connected in a twoelectrode system, where a rGO-coated SS filament was used as the working electrode and an SS filament was used as a combined reference and counter electrode (schematically shown in Figure 4c). The 3D braided electrochemical cell successfully detected $50 \mu \mathrm{M}$ DA in $100 \mathrm{mM}$ PBS utilizing CV and DPV techniques (Figure 4d and Figure 4e). The proposed electrode benefits from great flexibility and processability compared to other electrodes proposed for DA detection, e.g. modified glassy carbon electrodes ${ }^{17,49,50}$, modified laser scribed graphene ${ }^{3}$, modified screen printed electrodes ${ }^{16}$ and modified Pt electrodes ${ }^{2,19}$, which facilitate its incorporation into $3 \mathrm{D}$ electrochemical cells.
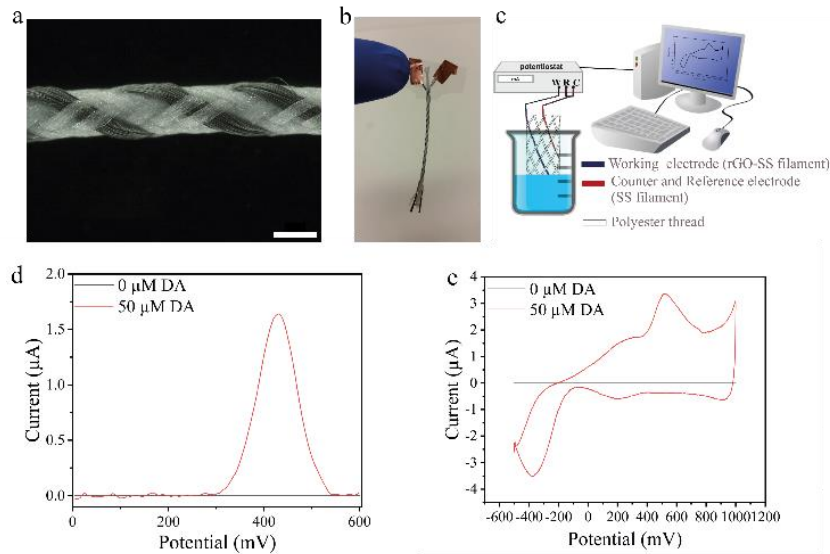

Figure 4-(a) optical micrograph of a 3D braided structure comprised of two parallel SS filaments separated by insulating PET yarns (scale bar: $1 \mathrm{~mm}$ ), (b) 3D textile electrochemical cell with rGO-SS filament working electrode, (c) schematic experimental setup using integrated electrodes in a 3D braided structure, (d) DPV and (e) CV (scan rate $100 \mathrm{mV} \mathrm{s}^{-1}$ ) of $50 \mu \mathrm{M}$ DA in $100 \mathrm{mM}$ PBS using integrated electrodes in a 3D braided structure (scan rate 100 $\mathrm{mV} \mathrm{s}^{-1}$ ) 
This study demonstrates a simple one-step method for production of a selective and sensitive fibre-based electrode for detection of DA utilising electrodeposition of rGO on SS filaments technique. This method provides a simple one-step technique to create a very low-cost electrode compared to $\mathrm{Pt}$ and CNT sensors being used to detect DA and eliminates any post-processing steps. As a proof of processability, the developed flexible yet strong electrode was successfully incorporated into a 3D braided structure and able to detect DA in a two-electrode system. The electrode benefits from features such as being low-cost, flexible and easy to use making it an excellent candidate for production of ASSURED devices. It also can be easily incorporated into electrochemical cells and wearable and portable sensors, tackles miniaturization issue and expands the application of textiles in point of care diagnostic devices and other integrated microfluidic chips in future.

\section{ASSOCIATED CONTENT}

\section{Supporting Information}

The Supporting Information is available free of charge on the ACS Publications website.

Materials and methods, optimizing the rGO deposition time on SS filaments. (PDF)

\section{AUTHOR INFORMATION}

\section{Corresponding Author}

*Email: alexrharris@gmail.com

\section{Notes}

The authors declare no competing financial interests.

\section{ACKNOWLEDGMENT}

The authors acknowledge funding support from the Australian Research Council Centre of Excellence Scheme (CE 140100012), Discovery Project (DP170102572), the Australian National Fabrication Facility (ANFF) -Materials Node under the National Collaborative Research Infrastructure Strategy providing nano- and micro-fabrication facilities for Australia's researchers, the facilities at the University of Wollongong Electron Microscopy Center, Dr. Patricia Hayes and Mr. Sepehr Talebain for their technical assistance.

\section{REFERENCES}

1 Y. Li, Y. Jiang, T. Mo, H. Zhou, Y. Li and S. Li, J. Electroanal. Chem., 2016, 767, 84-90.

2 W. Al-Graiti, Z. Yue, J. Foroughi, X.-F. Huang, G. Wallace, R. Baughman and J. Chen, Sensors, 2017, 17, 884.

3 G. Xu, Z. A. Jarjes, V. Desprez, P. A. Kilmartin and J. Travas-Sejdic, Biosens. Bioelectron., 2018, 107, 184-191.

4 A. R. Harris and G. G. Wallace, Adv. Funct. Mater., 2018, 28, 1-23.

5 I. M. Taylor, E. M. Robbins, K. A. Catt, P. A. Cody, C. L. Happe and X. T. Cui, Biosens. Bioelectron., 2017, 89, 400-410.

6 Y. Yan, Q. Liu, X. Du, J. Qian, H. Mao and K. Wang, Anal. Chim. Acta, 2015, 853, 258-264.

7 C. Huang, X. Chen, Y. Lu, H. Yang and W. Yang, Biosens. Bioelectron., 2015, 63, 478-482.

8 D. Rithesh Raj, S. Prasanth, T. V. Vineeshkumar and C. Sudarsanakumar, Sensors Actuators, B Chem., 2015, 224, 600-606.

9 A. J. Bandodkar and J. Wang, Trends Biotechnol., 2014, 32, 363-371.

10 K. Malzahn, J. R. Windmiller, G. Valdés-Ramírez, M. J. Schöning and J. Wang, Analyst, 2011, 136, 2912.

11 C. Yang, Q. Cao, P. Puthongkham, S. T. Lee, M. Ganesana, N. V. Lavrik and B. J. Venton, Angew. Chemie Int. Ed., 2018, 57, 1425514259.

12 P. Puthongkham, C. Yang and B. J. Venton, Electroanalysis, 2018, 30, 1073-1081.

13 I. M. Taylor, E. M. Robbins, K. A. Catt, P. A. Cody, C. L. Happe and X. T. Cui, Biosens. Bioelectron., 2017, 89, 400-410.

14 S. T. Barlow, M. Louie, R. Hao, P. A. Defnet and B. Zhang, Anal. Chem., 2018, 90, 10049-10055.
15 H. Wang, F. Ren, C. Wang, B. Yang, D. Bin, K. Zhang and Y. Du, RSC Adv., 2014, 4, 26895.

16 E. Fazio, S. Spadaro, M. Bonsignore, N. Lavanya, C. Sekar, S. G. Leonardi, G. Neri and F. Neri, J. Electroanal. Chem., 2018, 814, 9196.

17 M. Divagar, R. Sriramprabha, N. Ponpandian and C. Viswanathan, Mater. Sci. Semicond. Process., 2018, 83, 216-223.

18 M. Sajid, M. K. Nazal, M. Mansha, A. Alsharaa, S. M. S. Jillani and C. Basheer, TrAC - Trends Anal. Chem., 2016, 76, 15-29.

19 C. C. Harley, A. D. Rooney and C. B. Breslin, Sensors Actuators, B Chem., 2010, 150, 498-504.

20 C. Zhou, H. Zhang, Z. Li and W. Wang, Lab Chip, 2016, 16, $1797-$ 1811.

21 S. Alwarappan, G. Liu and C. Z. Li, Nanomedicine Nanotechnology, Biol. Med., 2010, 6, 52-57.

22 R. W. Peeling, K. K. Holmes, D. Mabey and a Ronald, Sex. Transm. Infect., 2006, 82 Suppl 5, v1-v6.

23 M. Reches, K. A. Mirica, R. Dasgupta, M. D. Dickey, M. J. Butte and G. M. Whitesides, ACS Appl. Mater. Interfaces, 2010, 2, 1722-8.

24 X. Li, J. Tian and W. Shen, ACS Appl. Mater. Interfaces, 2010, 2, 1-6.

25 D. Morris, S. Coyle, Y. Wu, K. T. Lau, G. Wallace and D. Diamond, Sensors Actuators B Chem., 2009, 139, 231-236.

26 G. Matzeu, L. Florea and D. Diamond, Sensors Actuators, B Chem., 2015, 211, 403-418.

27 V. F. Curto, C. Fay, S. Coyle, R. Byrne, C. O’Toole, C. Barry, S. Hughes, N. Moyna, D. Diamond and F. Benito-Lopez, Sensors Actuators B Chem., 2012, 171-172, 1327-1334.

28 S. Coyle, V. F. Curto, F. Benito-Lopez, L. Florea and D. Diamond, in Wearable Sensors, Elsevier, 2014, pp. 65-83.

29 J. R. Windmiller and J. Wang, Electroanalysis, 2013, 25, 29-46.

30 T.-H. Kang, North Carolina State University, 2006.

31 D. De Rossi, F. Carpi and F. Galantini, Adv. Sci. Technol., 2008, 57, 247-256.

32 J. Deignan, J. Foroughi, S. Farajikhah, A. Jeirani, P. Innis, G. G. Wallace and D. Diamond, in Advanced Materials World Congress, Stockholm, 2015.

33 A. Mirabedini, J. Foroughi, S. Farajikhah and G. G. Wallace, $R S C A d v$., 2016, 6, 108152-108152.

34 D. Esrafilzadeh, R. Jalili, E. M. Stewart, S. H. Aboutalebi, J. M. Razal, S. E. Moulton and G. G. Wallace, Adv. Funct. Mater., 2016, 26, 31053117.

35 S. Farajikhah, J. M. Cabot, P. C. Innis, B. Paull and G. Wallace, ACS Comb. Sci., 2019, 21, 229-240.

36 A. C. Glavan, A. Ainla, M. M. Hamedi, M. T. Fernández-Abedul and G. M. Whitesides, Lab Chip, 2016, 16, 112-119.

37 L. M. Ochiai, D. Agustini, L. C. S. Figueiredo-Filho, C. E. Banks, L. H. Marcolino-Junior and M. F. Bergamini, Sensors Actuators B Chem., 2017, 241, 978-984.

38 G. Baysal, S. Önder, İ. Göcek, L. Trabzon, H. Kızıl, F. N. Kök and B. Karagüzel Kayaoğlu, Sensors Actuators B Chem., 2015, 208, 475-484.

39 C. Zhao, S. Farajikhah, C. Wang, J. Foroughi, X. Jia and G. G. Wallace, Electrochem. commun., 2015, 61, 27-31.

40 S. Gambhir, E. Murray, S. Sayyar, G. G. Wallace and D. L. Officer, Carbon N. Y., 2014, 76, 368-377.

41 M. Mehrali, E. Sadeghinezhad, A. R. Akhiani, S. Tahan Latibari, S. Talebian, A. Dolatshahi-Pirouz, H. S. C. Metselaar and M. Mehrali, J. Clean. Prod., 2016, 137, 555-566.

42 E. Tegou, G. Pseiropoulos, M. K. Filippidou and S. Chatzandroulis, Microelectron. Eng., 2016, 159, 146-150.

43 M. Mehrali, A. R. Akhiani, S. Talebian, M. Mehrali, S. T. Latibari, A. Dolatshahi-Pirouz and H. S. C. Metselaar, J. Eur. Ceram. Soc., 2016, 36, 319-332.

44 S. Stankovich, D. A. Dikin, R. D. Piner, K. A. Kohlhaas, A. Kleinhammes, Y. Jia, Y. Wu, S. T. Nguyen and R. S. Ruoff, Carbon N. Y., 2007, 45, 1558-1565.

45 F. Tuinstra and J. L. Koenig, J. Chem. Phys., 1970, 53, 1126.

46 S. Pei and H. M. Cheng, Carbon N. Y., 2012, 50, 3210-3228.

47 Q. Liu, X. Zhu, Z. Huo, X. He, Y. Liang and M. Xu, Talanta, 2012, 97, 557-562.

48 K. Min and Y. J. Yoo, Talanta, 2009, 80, 1007-1011.

49 S. Daemi, A. A. Ashkarran, A. Bahari and S. Ghasemi, J. Colloid Interface Sci., 2017, 494, 290-299.

50 L.-Q. Xie, Y.-H. Zhang, F. Gao, Q.-A. Wu, P.-Y. Xu, S.-S. Wang, N.N. Gao and Q.-X. Wang, Chinese Chem. Lett., 2017, 28, 41-48. 
Table of Contents artwork

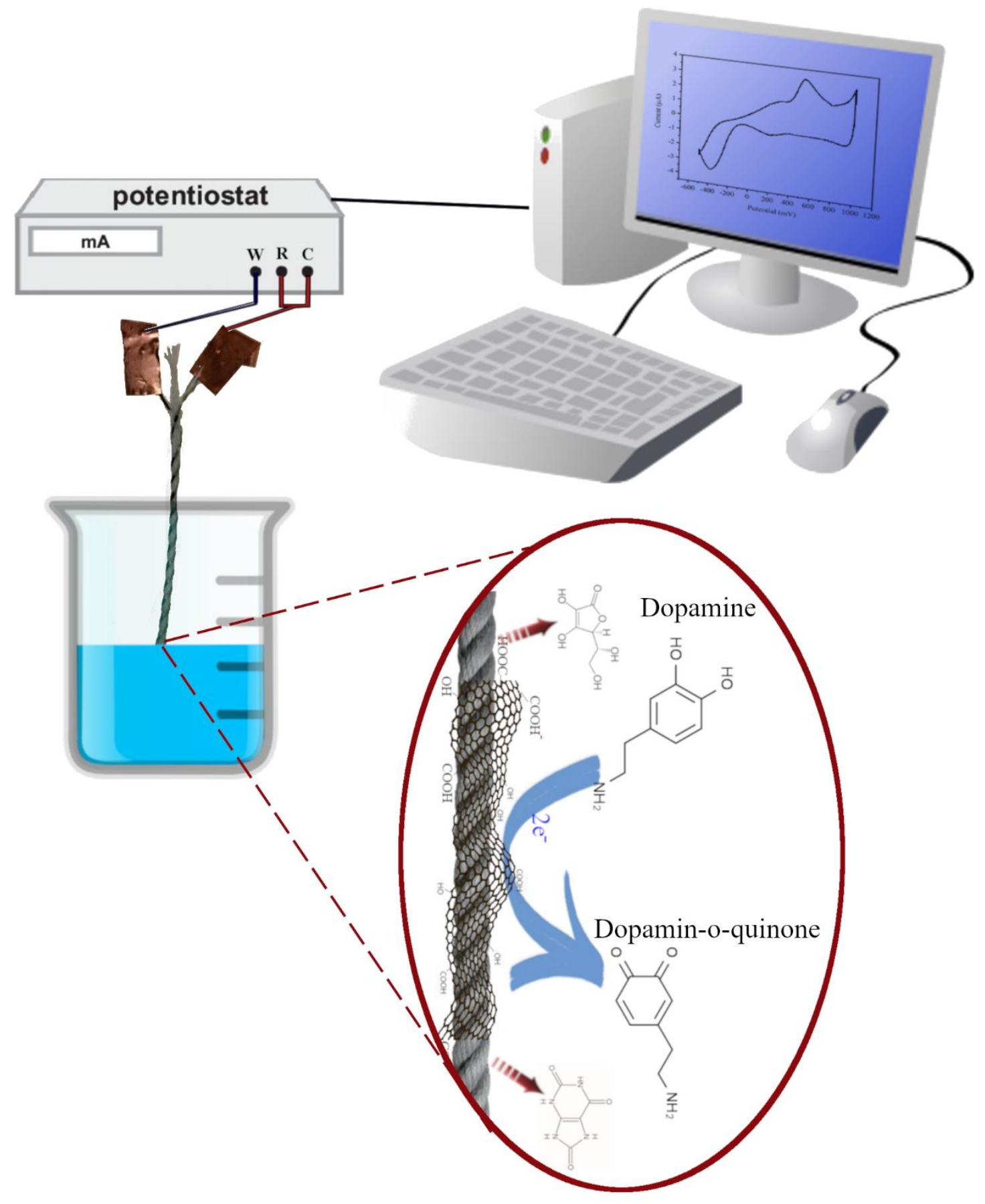

Keywords: fibre-based electrode, textile-based sensor, dopamine, graphene 